\title{
Crushing stones: Mechanical, intracorporeal and extracorporeal lithotripsy in the clearance of common bile duct lithiasis
}

Claude liguory, MD, Jean François Lefebvre, MD, Didier Bonnel, MD, Gary C Vitale, MD

\begin{abstract}
Mechanical, intracorporeal and extracorporeal lithotripsy were used in the treatment of common bile duct lithiasis in a series of 80 patients in whom initial extraction attempts with the Dormia basket and balloon catheter failed. Mechanical lithotripsy was performed in 74 cases and was successful in 38 (51.3\%). Among the 36 patients with failure of mechanical lithotripsy, five had an initial attempt at stone dissolution with methyl tert-butyl ether (MTBE) infused through a nasobiliary stent. This was successful in four cases; the stones did not disappear completely - however, they were smaller and easier to extract. Of the remaining 32 patients who failed mechanical lithotripsy, two underwent successfol surgical stone extraction with no further attempts at nonoperative treatment and 30 underwent complementary shock wave lithotripsy. Extracorporeal lithotripsy was used in 19 of these patients. The intracorporeal lithotripsy group of 21 patients comprised 11 with failed mechanical lithotripsy, six in whom no other treatment was attempted and four in whom extracorporeal lithotripsy had failed. Extracorporeal lithotripsy was successful in 15 cases (79\%) and intracorporeal lithotripsy in $19(90 \%)$. There were four treatment failures, with one patient death due to cholangitis and respiratory failure. In summary, mechanical lithotripsy is an effective and safe treatment modality but has a high failure rate. Extracorporeal lithotripsy is useful and should be attempted where available, but is not always successful. Intracorporeal lithotripsy is very efficient but requires either the transpapillary route, which is technically difficult, or the transhepatic route which carries associated complications. Can J Gastroenterol $1990 ; 4(9): 628-631$
\end{abstract}

Key Words: Common bile duct lithiasis, Extracorporeal lithotripsy, Intracorporeal lithotripsy, Mechanical lithotripsy

\section{La fragmentation des calculs: La lithotritie mécanique, intra-} corporelle et extra-corporelle dans la lithiase de la voie biliaire principale

RESUME: La lithotritie mécanique, intracorporelle et extra-corporelle a servi au traitement des lithiases du cholédoque dans une série de 80 patients chez qui des tentatives initiales d'extraction par sonde de Dormia et à ballonnet avaient

Clinique de L'Alma, Paris, France; and University of Louisville School of Medicine, Louisville, Kentucky, USA

Correspondence and reprints: Dr C Liguory, 7, Avenue de Breteville, 92200 Neuilly Sur Seine, France. Telephone (1) 47220440 $\prod \begin{aligned} & \text { HE ADVENTS OF ENDOSCOPIC } \\ & \text { retrograde cholangiopancreato }\end{aligned}$ graphy (ERCP) and endoscopic sphincterotomy have revolutionized the diagnosis and treatment of common bile duct lithiasis. Experience with the technique of Dormia basket stone ex. traction, however, has shown that in some cases stones must be crushed or fractured into smaller fragments before they can be removed endoscopically. This can frequently be problematic even in the presence of a large and technically well performed sphinctero. tomy. The occurrence of cholangitis as a corollary to persistent biliary obstruc. tion in these cases mandates develop. ment of prompt, effective and safe methods for stone fragmentation and removal. The present study focuses on the use of mechanical, intracorporeal and extracorporeal lithotripsy in patients with difficult to manage common bile duct lithiasis.

\section{PATIENTS AND METHODS}

From January 1985 through May 1989, 1040 endoscopic sphinctero. tomies were performed for suspected lithiasis at the Clinique de l'Alma. In 874 cases $(84 \%)$, sphincterotomy was done using the standard procedure with direct cannulation of the papilla using the sphincterotome. Precutting was necessary in 118 cases $(11.4 \%)$, peroral transpapillary guidance in $30(2.9 \%)$, and percutaneous transhepatic 
échoué. Une lithotritie mécanique a été effectuée chez 74 patients et a réussi chez $38(51 \%)$ d'entre eux. Cinq des 36 patients chez qui elle n'a pas abouti avaient subi une tentative initiale de dissolution des calculs au méthyl tert-butyl éther (MTBE) instillé par sonde nasobiliaire. La procédure avait réussi dans quatre cas dans la mesure où, même si les lithiases n'avaient pas complètement disparues, elles étaient désormais réduites et d'extraction plus facile. Chez les 32 autres patients pour qui la lithotritie mécanique a échoué, deux ont subi l'extraction chirurgicale réussie de leurs calculs sans autre forme de traitement non opératoire, et 30 ont subi une lithotritie complémentaire par ondes de chocs. On a procédé à une lithotritie extra-corporelle chez 19 de ces patients. Le groupe soumis à une lithotritie intra-corporelle comptait 21 patients, parmi lesquels 11 avaient subi une lithotritie mécanique sans résultat, six n'avaient reçu aucun autre traitement et quatre pour qui la lithotritie extra-corporelle avait échoué. La lithotritie extra-corporelle avait réussi chez $15(79 \%)$ patients et la lithotritie intra-corporelle, chez 19 (90\%). On relève quatre échecs de traitement, avec un décès dû à une cholangite et à une insuffisance respiratoire. En résumé, la lithotritie mécanique est une modalité thérapeutique efficace et sûre mais son taux d'échec est élevé. La lithotritie extra-corporelle est utile et devrait être tentée si possible, mais elle n'aboutit pas toujours. La lithotritie intra-corporelle est très efficace mais requiert soit une voie transpapillaire (techniquement difficile) soit une voie transhépatique, qui a ses complications propres.

guidance in $16(1.5 \%)$. There were two cases $(0.2 \%)$ in which the papilla could not be reached by the endoscopic route, and a percutaneous transhepatic sphincterotomy was performed. The endoscopic sphincterotomy was not possible even with precutting in 12 cases and these subsequently underwent transhepatic guided endoscopic sphincterotomy after passage of a drain across the papilla using a transhepatic approach. Thus, using a combination of endoscopic and radiologic approaches, all 1040 patients were able to have successful sphincterotomies. There were 49 patients $(4.7 \%)$ in this series who had been referred by other centres because of unsuccessful endoscopic sphincterotomy.

There were 512 patients $(49.3 \%)$ with both gallbladder and common bile duct lithiasis, 375 (36\%) with late residual common duct lithiasis and 153 (14.7\%) with postoperative common bile duct lithiasis with $\mathrm{T}$-tube in place. Table 1 delineates results in these patient groups. After initial extraction attempts with the Dormia basket and balloon catheter techniques, there were 80 patients $(9.7 \%)$ with common bile duct stones which could not be extracted. These patients had a mean age of $76 \pm 4$ years and mean size of stones was $22.5 \pm 10.4 \mathrm{~mm}$. Stones were multiple in 29 cases (36\%) (Table 2).
The standard protocol for common bile duct lithiasis after failure of standard techniques was as follows: mechanical lithotripsy was the first procedure used following unsuccessful standard basket and balloon extraction. With this technique, the stone is placed in a Dormia basket and a mechanical system is attached which allows traction of 30 to $50 \mathrm{~kg}$ on the wire. Stone fragmentation thus occurs due to the mechanical force applied on the wires of the Dormia basket surrounding the stone. If mechanical lithotripsy failed, patients were assigned to undergo either extracorporeal or intracorporeal shock wave lithotripsy. Usually, patients with a single large stone were selected initially for extracorporeal lithotripsy while those with multiple stones, or those in whom stone imaging was felt to be a significant potential problem, went directly to intracorporeal lithotripsy.

Extracorporeal lithotripsy was performed using either the modified HM3 Dornier or Technomed Sonolith 3000 electrohydraulic lithotripter. The Dornier lithotripter uses radiographic techniques of stone localization, while the Technomed system uses ultrasound localization. Intracorporeal electrohydraulic lithotripsy was performed with a Walz electronic generator which delivers a spark at the tip of a probe. The
TABLE 1 Results of stone extraction with con-
ventional procedures

Type of lithiasis Cases
$\begin{aligned} & \text { Successful } \\ & \text { extraction }\end{aligned}$
$\begin{aligned} & \text { Combladder in place } \\ & \text { stone gallbladder }\end{aligned}$
$\begin{aligned} & \text { Gallbladder removed } \\ & \text { Early residual } \\ & \text { stone }\end{aligned}$
$\begin{aligned} & \text { Late residual or } \\ & \text { recurrent stone }\end{aligned}$
$\begin{aligned} & \text { retube in place } \\ & \text { T-tube }\end{aligned}$

- T-tube in place

\section{TABLE 2}

\section{Unextractable stones}

\begin{tabular}{lc}
\hline Number of patients & 80 \\
Age (years) & $76 \pm 14$ \\
Size of stones (mm) & $22.5 \pm 10.2$ \\
Multiple stones & 29 patients (36\%) \\
\hline
\end{tabular}

probe is $1.6 \mathrm{~mm}$ in diameter and can be introduced into the common bile duct through the operating channel of the standard side-viewing endoscope or the choledochoscope (mother/baby-scopy system for peroral access, or the standard choledochoscope for transhepatic access). The spark generated by this device, delivered in an ionized solution, creates a shock wave which is very effective in fragmenting biliary stones.

Early in the study period, five patients underwent stone dissolution attempts with methyl tert-butyl ether (MTBE) infused through a nasobiliary catheter. This technique was not frequently used, primarily due to the success of the other techniques and the perceived higher risk (not based on the authors' experience) of MTBE infusion.

\section{RESULTS}

Mechanical lithotripsy was performed in 74 cases and was successful in 38 (51.3\%). Among the 36 patients with failure of mechanical lithotripsy, five had an attempt at stone dissolution with MTBE infused through a nasobiliary stent. This was successful in four cases in that although the stones did not disappear completely, they were smaller, smoother and easier to extract. Of the remaining 32 patients, two un- 
TABLE 3

Intracorporeal shockwave lithotripsy

\begin{tabular}{lcc}
\hline & $\begin{array}{c}\text { No. of } \\
\text { patients }\end{array}$ & Successful \\
\hline Access route & 15 & 14 \\
Transhepatic & 4 & 4 \\
Transpapillary & 2 & 1 \\
$\begin{array}{l}\text { Choledochoduo- } \\
\text { denal anastomosis }\end{array}$ & & \\
Total & 21 & $19(90 \%)$ \\
\hline
\end{tabular}

derwent successful surgical stone extraction with no further attempts at nonoperative stone crushing. There were thus 30 patients who required complementary shock wave lithotripsy from this group. Extracorporeal lithotripsy was used in 19 cases. The intracorporeal lithotripsy patient group of 21 patients comprised 11 with failed mechanical lithotripsy, six in whom no other treatment was attempted and four in whom extracorporeal lithotripsy failed.

Extracorporeal lithotripsy was successful in 15 cases (79\%) and failed in four $(21 \%)$. The intracorporeal lithotripsy was performed by a transpapillary route in four cases, by percutaneous transhepatic cholangioscopy in 15 cases, and through a choledochoduodenal anastomosis with an axial scope in two. The procedure was successful in all four transpapillary cases, 14 of 15 transhepatic and one of two with choledochoduodenal anastomoses. Thus, intracorporeal lithotripsy was ultimately successful in 19 of 21 cases $(90 \%)$ in which it was tried (Table 3). Successful extraction of stones by either conventional techniques or after lithotripsy or MTBE infusion was possible in 1036 of 1040 cases (99.6\%).

Among the four patients in which the procedure failed, one died before another treatment because of cholangitis and respiratory failure, one had endoscopic stenting and two underwent surgery. The mortality rate was thus $1.3 \%$ among the 80 patients with endoscopically difficult to manage common bile duct stones. Complications related to lithotripsy included two cases of hemobilia in the transhepatic dilation tract and two cases of cholangitis in the percutaneous cholangioscopy group.

\section{DISCUSSION}

Mechanical lithotripsy is a simple procedure but the failure rate is high, approximating 50\%; it is especially problematic when stones are big or occlusive (1). The common cause for failure is the inability to effectively capture the stone in the Dormia basket (1). Whether the stones are single or multiple does not seem to affect the applicability or success of the procedure, although the time spent to complete stone removal is directly dependent on stone mass. Although some workers report a success rate of $82.4 \%$ with mechanical lithotripsy $(2,3)$, their patients may be different from the present series in that mechanical lithotripsy failure was due primarily to inability to surround very large stones with the Dormia basket. The use of a shorter sphincterotomy can lead to a higher percentage of smaller stones which are inextractable but more suited to mechanical lithotripsy.

Extracorporeal shock wave lithotripsy is a safe and effective treatment modality, but may not be available in every centre in which endoscopic sphincterotomy is performed. Early results with this technique in many institutions are very promising (4-6). In several trials, successful fragmentation rates range from 71 to $94.6 \%$ with common bile duct clearance in 41.5 to $86 \%$ one to four days following lithotripsy sessions (7. 10). Adjunctive measures such as endoscopic extraction or nasobiliary drain with lavage are used routinely to obtain satisfactory stone clearance rates. It is the only treatment required in approximately $50 \%$ of cases $(7,11)$. Cholangitis and pancreatitis are potential complications. Intrahepatic stones, after failure of removal by other methods, may be particularly amenable to extracorporeal shock wave lithotripsy (12). Groen et al (13) report a novel technique of transhepatic balloon dilation of the sphincter of Oddi accompanied by extracorporeal shock wave lithotripsy to treat patients with endoscopically inaccessible papillas. More work is needed with this technique to verify its use and efficacy.

Intracorporeal electohydraulic lithotripsy is very efficient but requires either the transpapillary route or percutaneous transhepatic cholangioscopy (14). The transpapillary route is technically difficult and transhepatic cholangioscopy has significant complications related to puncture of the bile duct and tract dilation to accommodate the scope namely, hemobilia and cholangitis (15).

Finally, danger of common bile duct injury exists if placement of the probe is not very well controlled under direct vision (16). The disadvantage of trans: hepatic endoscopic guidance is the need for tract dilation which prolongs hospitalization and increases the incidence of hemorrhagic complications (17). The peroral route for mother/ baby-scope systems avoids this neces. sity but needs two well trained endoscopists as the baby-scope is extremely fragile. The optimal technique for use of intracorporeal hydroelectric shock wave lithotripsy, which is a very effec. tive stone fracture method, has yet to be elucidated in the authors' opinion; the peroral cholangioscopic route is presently their preferred option when technically feasible.

At present, the authors' treatment of retained or primary common bile duct stones is as follows. Standard diagnostic ERCP followed by endoscopic sphincterotomy and Dormia basket stone extraction remains the initial procedure of choice. If sphincterotomy cannot be performed in a standard fashion or by guidewire insertion, a transhepatic guided endoscopic sphinc. terotomy may be performed. After suc. cessful sphincterotomy, mechanical lithotripsy should be attempted in all cases as it works in $50 \%$ of cases, can be performed immediately and incurs minimal or no morbidity for failed cases. If the mechanical technique is not suc. cessful, extracorporeal shock wave lithotripsy should be tried next if it ap. pears at all technically feasible. In the authors' experience, it may be tried for one or two stones, but is unlikely to be successful for larger numbers of stones and probably should be bypassed in favour of intracorporeal techniques (18). Intracorporeal lithotripsy, particularly when accessed by the peroral cholangioscopic route, can be per. 
formed directly at the time of initial sphincterotomy or can be reserved for failures of extracorporeal lithotripsy depending on local expertise. The transhepatic route should be used only in case of failure of other lithotripsy techniques (mechanical, extracorporeal, intracorporeal via peroral route) or in special anatomic conditions (intrahepatic stones, recurrent stones after Roux-en-Y anastomosis). The development of new balloon catheter hydro-

\section{REFERENCES}

1. Liguory C, Lefebvre JF, Bonnel D, Beaugerie L, Canard JM, Etienne JP. Lithotritie mécanique des calculs de la voie biliaire principale. Chirurgie 1987;113:556-61.

2. Riemann JF, Seuberth K, Demling L. Mechanical lithotripsy of common bile duct stones. Gastrointest Endosc 1985;31:207-10.

3. Riemann JF, Seuberth K, Demling L. Mechanical lithotripsy through the intact papilla of Vater. Endoscopy 1983;15:111-3.

4. Liguory C, Lefebvre JF, Beaugerie L, et al. Lithotritie extracorporelle: Resultats preliminaires che 5 malades ayant des calculs de la voie biliaire principale. Presse Med 1987;16:1505-7.

5 Sackmann M, Sauerbruch T, Delius M, Holl J, Brendel W, Paumgartner G. Biliary stones: Treatment by shockwave lithotripsy. Surg Endosc 1988;2:224-6.

6. Taylor MC, Marshall JC, Fried LA, LeBrun GP, Norman RW. Extracorporeal shock wave lithotripsy (ESWL) in the management of complex biliary tract stone disease. Ann Surg 1988;208:586-92.

7. Bland KI, Jones RS, Maher JW, et al. electric shock techniques may allow safe direct stone fracture through the operating channel of a standard scope, but these techniques are still under development. The risk of common duct injury from the use of the hydroelectric probe is high if stone fracture is not performed under direct vision.

After endoscopic sphincterotomy, stone extraction can be successfully performed by conventional methods in more than $90 \%$ of cases. With the addi-

Extracorporeal shock-wave lithotripsy of bile duct calculi. An interim report of the Dornier US Bile Duct Lithotripsy Prospective Study. Ann Surg 1989;209:743-53.

8. Moody FG, Amerson JR, Berci G, et al. Lithotripsy for bile duct stones. Am J Surg 1989;158:241-7.

9. Sauerbruch T, Stern M. Fragmentation of bile duct stones by extracorporeal shock waves. A new approach to biliary calculi after failure of routine endoscopic measures, Gastroenterology 1989;96:146-52

10. Burhenne HJ, Becker CD, Malone DE, Rawat B, Fache JS. Biliary lithotripsy: Early observations in 106 patients. Work in progress. Radiology 1989;171:363-7.

11 Fried LA, LeBrun GP, Norman RW, et al. Extracorporeal shock-wave lithotripsy in the management of bile duct stones. Am J Radiol 1988;151:923-6.

12. Wenzel H, Greiner L, Jakobeit C, Lazica M, Thuroff J. Extrakorporale Stosswellenlithotripsie von Gallengangssteinen. Dtsch Med Wochenschr 1989;114:738-43.

13. Groen JN, Lock MT, Lameris JS, van Blankenstein M, Terpstra OT. tion of lithotripsy techniques, a successful result is possible in greater than $99 \%$ of cases with an acceptable minimal morbidity incurred by the addition of these techniques to the treatment protocol. The key to successful stone removal is the ability to selectively cannulate the bile duct, and efforts to improve outcome with stone management should begin with a careful assessment of cannulation and sphincterotomy techniques for the difficult papilla.

Removal of common bile duct stones by the combination of percutaneous balloon dilatation and extracorporeal shock-wave lithotripsy.

Gastroenterology 1989;97:202-6,

14. Tanaka M, Yoshimoto $\mathrm{H}$, Ideka S, Matsumoto S, Xuan GR. Two approaches for electro-hydraulic lithotripsy in the common bile duct. Surgery 1985;98:313-8.

15. Lear JL, Ring EA, Macoviak JA, Baum S. Percutaneous transhepatic electrohydraulic lithotripsy. Radiology 1984;150:589-90.

16. Liguory C, Bonnel D, Canard JM, Cornud F, Dumont JL. Intracorporeal electrohydraulic shock wave lithotripsy of common bile duct stones: Preliminary results in seven cases. Endoscopy 1987;19:237-40.

17. Hwang MH, Mo LR, Yang JC, Lin C. Percutaneous transhepatic cholangioscopic, ultrasonic lithotripsy in the treatment of retained or recurrent intrahepatic stone. Gastrointest Endosc 1987;33:303-6.

18. Liguory C, Lefebvre JF, Bonnel D. Apport des différentes techniques de lithotripsie dans le traitement des calculs de la voie biliarie principale. Acta Gastroenterol Belg 1988;51:251-6. 


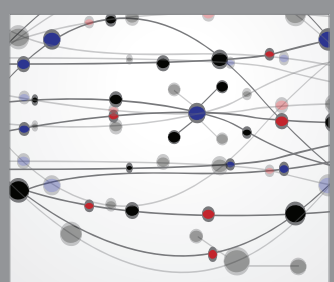

The Scientific World Journal
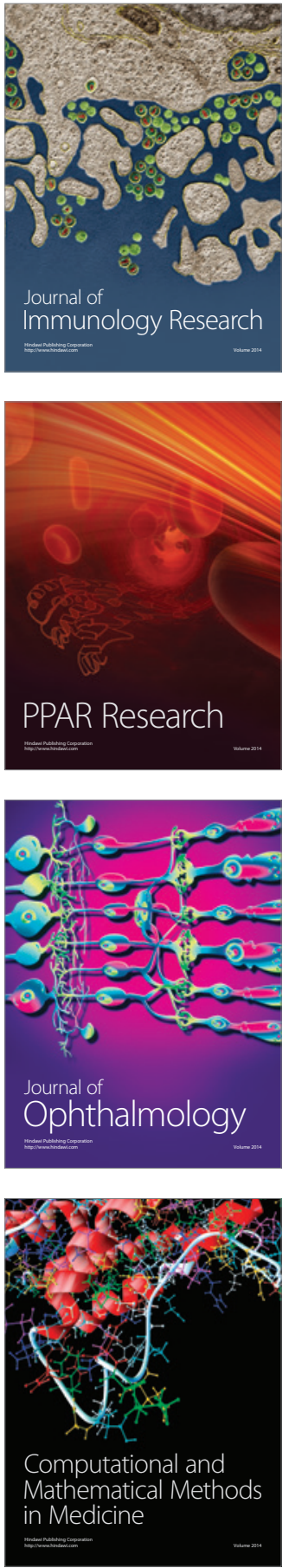

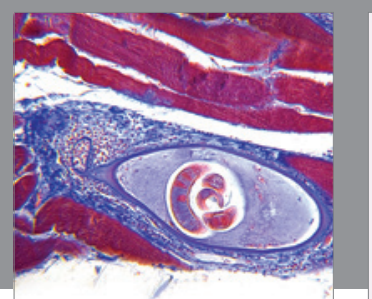

Gastroenterology Research and Practice

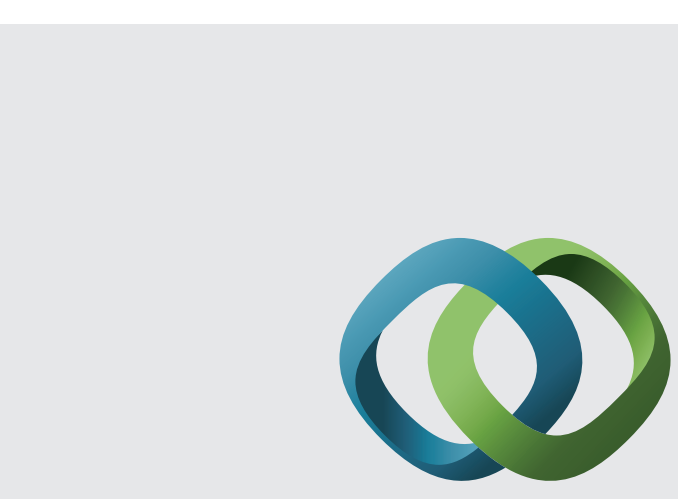

\section{Hindawi}

Submit your manuscripts at

http://www.hindawi.com
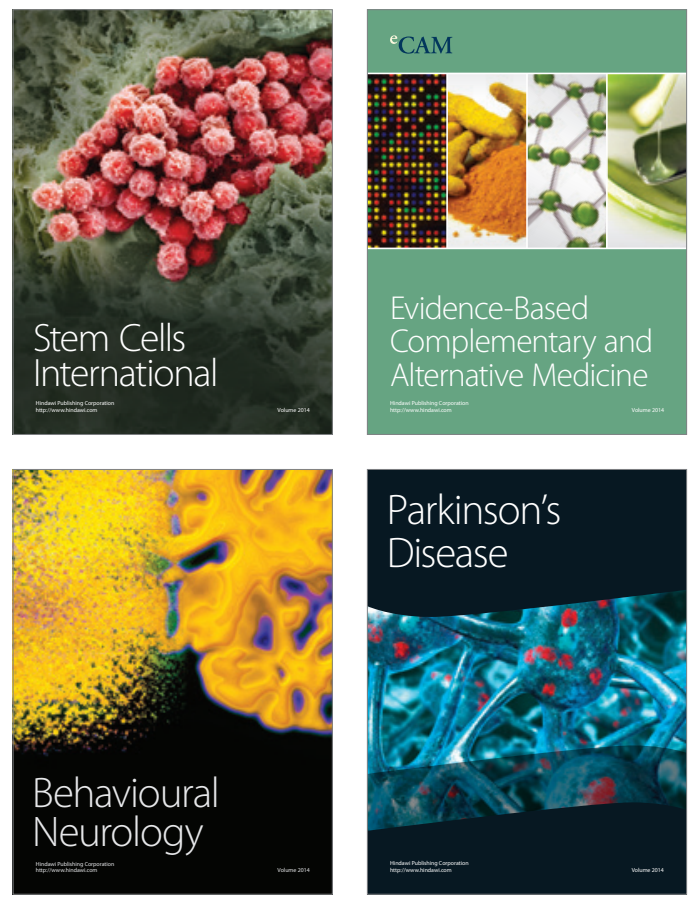
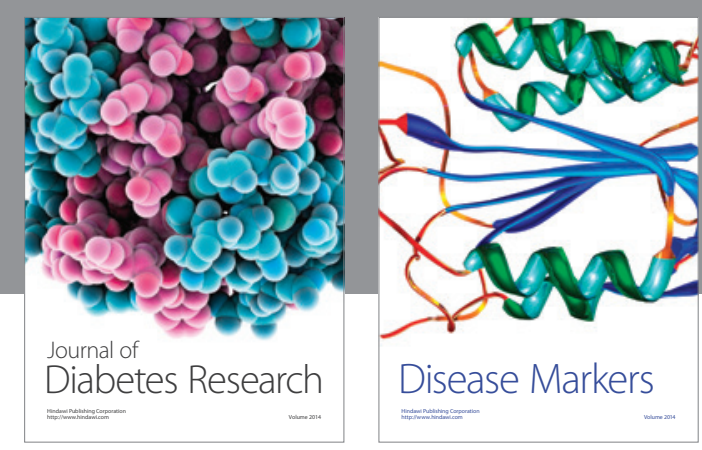

Disease Markers
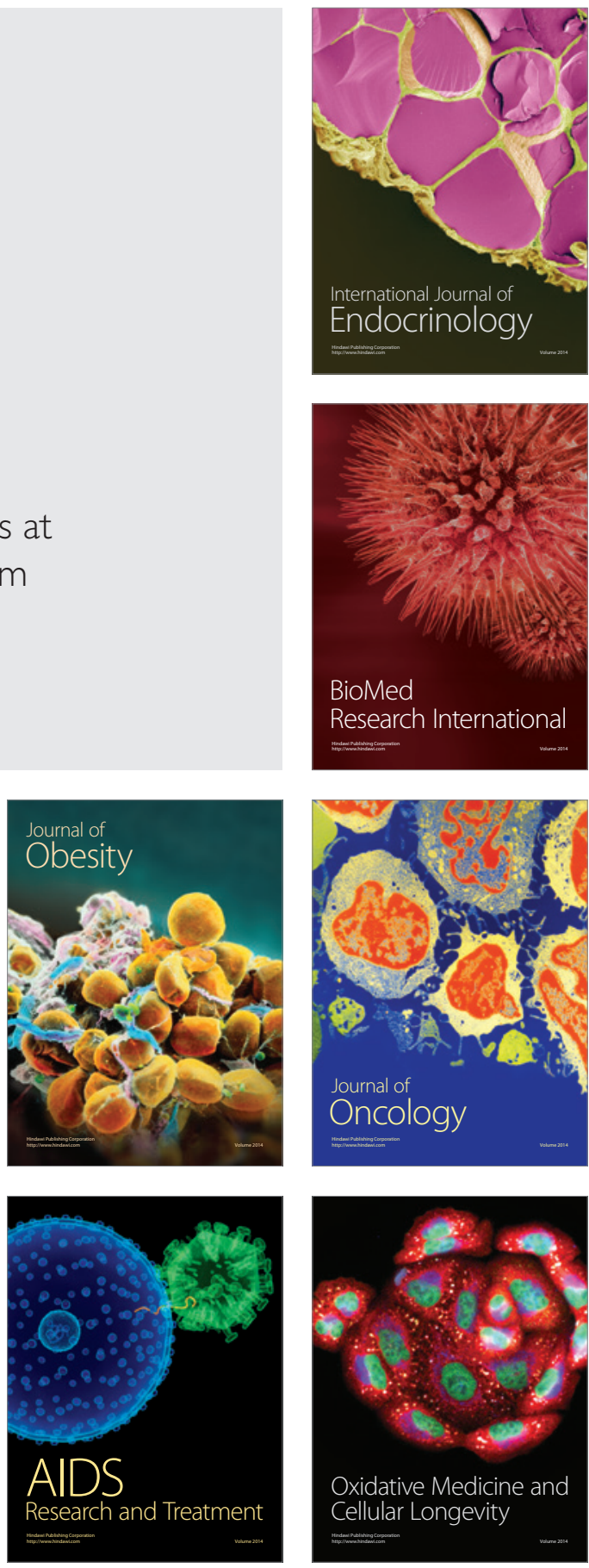